\title{
Fitossociologia do estrato herbáceo-subarbustivo de uma área de campo sujo no Distrito Federal, Brasil ${ }^{1}$
}

\author{
Cássia Beatriz Rodrigues Munhoz ${ }^{2,4}$ e Jeanine Maria Felfili ${ }^{3}$
}

Recebido em 19/04/2005. Aceito em 22/03/2006

\begin{abstract}
RESUMO - (Fitossociologia do estrato herbáceo-subarbustivo de uma área de campo sujo no Distrito Federal, Brasil). O campo sujo consiste basicamente de um estrato herbáceo sub-arbustivo dominado por gramíneas, alguns arbustos esparsos e indivíduos arbóreos normalmente menos desenvolvidos de espécies de cerrado sentido restrito. O objetivo desse estudo foi avaliar a estrutura fitossociológica do estrato herbáceo-subarbustivo, em diferentes períodos de amostragem, em uma área de campo sujo localizada na Fazenda Água Limpa,

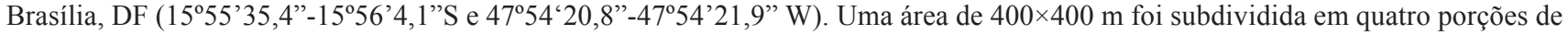
$200 \times 200 \mathrm{~m}$ onde foram sorteadas linhas de $40 \mathrm{~m}$. No levantamento fitossociológico adotou-se o método de interseção na linha. Foram amostradas 163 espécies, incluídas em 78 gêneros e 39 famílias. A família mais importante foi Poaceae com 67,04\% de cobertura. A similaridade de Sørensen entre as quatro linhas amostradas foi alta, entre 0,60 e 0,69 , provavelmente devido à homogeneidade do solo da área. A similaridade entre os cinco períodos de inventário também foi alta, pois as espécies mais importantes variam pouco as suas taxas de cobertura ao longo do ano. No entanto, para o estrato herbáceo recomenda-se mais de uma amostragem por ano, para se registrar as espécies com baixa freqüência e cobertura e com ciclo de vida curto.
\end{abstract}

Palavras-chave: Campo sujo, método de interseção na linha, similaridade, estrato herbáceo, fogo

\begin{abstract}
Phytosociology of the herb-subshrub layer in an area of campo sujo, Distrito Federal, Brazil). Campo sujo consists of an herbaceous/sub-shrub layer dominated by grasses with some scattered shrubs of poorly developed cerrado sensu stricto species. We did a phytosociological survey of the herbaceous/sub-shrub layer of a campo sujo at the Água Limpa Farm, Brasília, DF (1555'35,4'”$15^{\circ} 56^{\prime} 4,1^{\prime \prime} \mathrm{S} ; 47^{\circ} 54^{\prime} 20,8^{\prime}$ ' $-47^{\circ} 54^{\prime} 21,9^{\prime \prime} \mathrm{W}$.) by sampling over time. We randomly set 40-meter transects inside a $400 \times 400 \mathrm{~m}$ plot divided in four quadrats of $200 \times 200 \mathrm{~m}$. The line intercept method was adopted for sampling where each line was divided in $1 \mathrm{~m}$ sections. We found a total of 163 species belonging to 78 genera and 39 families. Poaceae was the most important family with $67.04 \%$ of cover. Sørensen's similarity indices were high (0.60 to 0.69$)$ when comparing the transections, probably due to the uniform soil. The similarity between sampling periods was also high probably because there was little variation in cover rates for the main species over the year. However, sampling more than once a year seems to be necessary to register rarer, low-cover and ephemeral species.
\end{abstract}

Key words: Cerrado, line intercept method, similarity, herbaceous layer, fire

\section{Introdução}

O status do estrato herbáceo-subarbustivo é um fator considerado para a classificação fisionômica das savanas, onde são levadas em consideração as estruturas, a mudança no aspecto vegetativo durante o ano, a forma de crescimento, a consistência e o tamanho das folhas (Eiten 1979). O Cerrado apresenta um gradiente fisionômico de campo limpo, onde as árvores cobrem menos de $10 \%$ do terreno, até o cerradão com $70 \%$ de cobertura de copas (Ribeiro \& Walter 1998). O componente dominante nas fisionomias mais abertas é o estrato herbáceo-subarbustivo. As fisionomias campestres ocorrem normalmente na transição entre as matas e o cerrado sentido restrito, desempenhando uma importante ligação entre essas fisionomias (Eiten 1979).

Embora o estrato herbáceo-subarbustivo seja dominante em vários tipos fisionômicos da vegetação de Cerrado e apresente grande riqueza de espécies (Felfili et al. 1994; Mendonça et al. 1998; Batalha \& Martins 2002; Tannus \& Assis 2004), sua flora tem sido pouco estudada, principalmente sob o ponto de vista quantitativo (Mantovani \& Martins 1993; Felfili

\footnotetext{
1 Parte da Tese de Doutorado da primeira Autora desenvolvida na Universidade de Brasília

2 Universidade Católica de Brasília, Curso de Biologia, QS7 Lote 01 EPCT, Águas Claras, 72030-170 Taguatinga, DF, Brasil

3 Universidade de Brasília, Departamento de Engenharia Florestal, C. Postal 04357, 71919-970 Brasília, DF, Brasil

4 Autor para correspondência: cassia@ucb.br
} 
et al. 1994; Guimarães et al. 2002; Meirelles et al. 2002).

O conhecimento dos padrões de distribuição de espécies numa área pode contribuir para a compreensão dos principais fatores ambientais que estão determinando a estrutura da comunidade (Felfili 1998). Para o Cerrado são raros os trabalhos sobre a distribuição sazonal e espacial das espécies do estrato herbáceo-subarbustivo (Guimarães et al. 2002). Goldsmith (1974), em um estudo que utilizou análises multivariadas em comunidades herbáceo-subarbustivas no Brasil Central (leste do Mato Grosso), classificou a vegetação em dois grandes tipos: Campos secos (Dry grasslands), que ocorre sobre solos rasos em montanhas de arenito e laterita em áreas dominadas pela savana com vegetação lenhosa (cerrado) e Campos úmidos (Moist Grasslands) que ocorre em vales geralmente bordeando as matas de galeria. $\mathrm{O}$ autor conclui que a umidade parece ser o determinante principal da variação na vegetação e que as espécies têm diferentes graus de tolerância à umidade do solo.

São poucos os estudos que avaliaram as mudanças quantitativas na composição de espécies do estrato herbáceo-subarbustivo de cerrado no tempo. Silva \& Nogueira (1999), estudando o estrato herbáceoarbustivo em uma área de cerrado sentido restrito encontraram uma pequena variação temporal na distribuição das espécies ao longo do ano. Maior variação temporal na composição de espécies ao longo do ano foi encontrada em um campo sujo estudado por A.A.A. Barbosa (dados não publicados), porém esse estudo não apresenta dados de freqüência relativa das ervas graminóides, subestimando a família Poaceae, considerada a mais importante no estrato herbáceo (Mantovani \& Martins 1993; Felfili et al. 1998; Batalha \& Martins 2002).

Informações sobre o efeito do fogo na composição florística e na estrutura da vegetação em ecossistemas de Cerrado ainda são restritas. Pesquisas em savanas Venezuelanas queimadas mostraram que o fogo exerce um efeito de poda na vegetação favorecendo as espécies menores e mais delgadas que têm dificuldades de crescer sobre a massa vegetal seca acumulada na camada herbácea sem fogo (Canales et al. 1994). Estudos em áreas de campo sujo e de cerrado sentido restrito mostram que a ação das queimadas acelera a ciclagem de nutrientes, exerce efeito de poda, promovendo uma imensa capacidade regenerativa, uma profusa floração de muitas espécies que dependem deste evento para florescer, bem como a dispersão de sementes (Coutinho 1977; 1982). Os efeitos do empobrecimento da vegetação, do estrato rasteiro, em termos do número de espécies, têm sido observados em áreas de cerrado onde não há fogo por muito tempo (Coutinho 1979; Eiten 1992; Eiten \& Sambuichi 1996; Moreira 1996).

O estrato herbáceo-subarabustivo é um componente importante no Cerrado tanto do ponto de vista biológico como por sua utilização econômica, por exemplo, mais de 90 milhões de hectares são utilizados como pastagem nativa (Haridasan 1996). Apesar disso, há pouco conhecimento sobre os requisitos nutricionais das plantas no solo, as adaptações e a distribuição espacial e temporal das espécies desse componente. Alterações que possam ocorrer na composição florística do estrato herbáceo-subarabustivo como conseqüência de desmatamento, queimadas, herbivoria e extrativismo têm sido, também, pouco investigados. Estudos sobre a estrutura e a dinâmica deste estrato da vegetação e das variáveis ambientais dos ecossistemas de cerrado são essenciais para o delineamento de estratégias para a conservação da sua diversidade biológica, assim como para o uso sustentável destes.

Este trabalho objetivou avaliar a mudança na estrutura fitossociológica no período de um ano, após um incêndio, em uma área de campo sujo. Partiu-se do pressuposto que existe, ao longo do ano, uma mudança sazonal na riqueza e na cobertura das espécies do estrato herbáceo-subarbustivo de campo sujo.

\section{Material e métodos}

Localização e descrição geral da área - Este estudo foi conduzido em uma área de campo sujo, na Fazenda Água Limpa - FAL, situada ao sul do Distrito Federal, de propriedade da Universidade de Brasília e área nuclear da Reserva da Biosfera do Cerrado. O campo sujo estudado localiza-se próximo à mata de galeria do córrego Taquara $\left(15^{\circ} 55^{\prime} 35,4^{\prime \prime}-15^{\circ} 56^{\prime} 4,1^{\prime \prime} \mathrm{S}\right.$ e $\left.47^{\circ} 54^{\prime} 20,8^{\prime}{ }^{\prime}-47^{\circ} 54^{\prime} 21,9^{\prime \prime} \mathrm{W}\right)$. A área não era queimada há seis anos e sofreu uma queimada acidental na primeira semana de agosto de 1999, cerca de três meses antes do início deste trabalho.

O campo sujo estudado encontra-se sobre Latossolo profundo de baixa fertilidade e com lençol

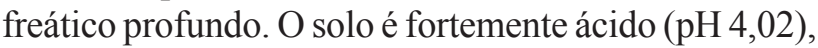
com níveis de alumínio elevados $\left(0,35 \mathrm{cmolc} / \mathrm{dm}^{3}\right)$, baixos teores de cálcio $\left(0,35 \mathrm{cmolc} / \mathrm{dm}^{3}\right)$, magnésio $\left(0,12 \mathrm{cmolc} / \mathrm{dm}^{3}\right)$ e fósforo $\left(1,14 \mathrm{cmolc} / \mathrm{dm}^{3}\right)$ (C.B.R. Munhoz, dados não publicados). 
O clima da região é do tipo Aw, segundo a classificação de Köppen e caracteriza-se por duas estações bem definidas: uma quente e chuvosa (de outubro a abril) e outra fria e seca (de maio a setembro). A temperatura média anual máxima é de $28,5{ }^{\circ} \mathrm{C}$ e a média anual mínima de $12,0{ }^{\circ} \mathrm{C}$. A precipitação média anual do período estudado, de novembro/1999 a dezembro/2000, foi de $1.500 \mathrm{~mm}$, medida na estação meteorológica da Reserva Ecológica do IBGE.

Método de Amostragem - Na porção central de um campo sujo próximo à mata de galeria do córrego Taquara foi selecionada uma área de $400 \times 400 \mathrm{~m}$ que foi subdividida em quatro quadrados de $200 \times 200 \mathrm{~m}$. Em cada quadrado sorteou-se uma linha de $40 \mathrm{~m}$ perpendicular à borda da mata onde foram efetuadas as amostragens, as linhas sorteadas são aqui denominadas CS1, CS2, CS3 e CS4 (Fig. 1). O primeiro inventário fitossociológico foi realizado no mês de novembro/1999 (início da estação chuvosa). As demais amostragens foram realizadas nos meses de abril (final da estação chuvosa), julho (auge da estação seca), outubro (final da estação seca) e dezembro/2000 (auge da estação chuvosa), de modo que a área foi monitorada por 13 meses. As espécies amostradas na área foram reunidas em grupos de período de ocorrência, associados às estações seca e chuvosa e ao fogo ocorrido no campo sujo.

Foi utilizado o método de interseção na linha (Canfield 1941; 1950), para a determinação da composição e da cobertura linear das espécies. O método consiste em traçar linhas sobre a vegetação a ser amostrada e anotar o comprimento que a linha é interceptada por uma espécie, que dividido pelo comprimento total das espécies inventariadas sob a linha, estima a proporção da área coberta por aquela espécie. Neste estudo, cada linha sorteada foi demarcada e subdividida com varetas de ferro em segmentos de $1 \mathrm{~m}$ que representaram as unidades amostrais (UA) para a análise fitossociológica. Com o auxílio de uma vareta de $1 \mathrm{~m}$, demarcada com uma fita métrica, colocada sobre cada UA, fez-se a visualização da projeção horizontal da linha na qual eram considerados todos os indivíduos com hábito herbáceo ou subarbustivo. Eram registradas a ocorrência e a projeção horizontal de cada espécie, isto é o comprimento que cada espécie ocupava por UA ao longo das linhas amostradas, perfazendo um total de 160 UA de $1 \mathrm{~m}$ inventariados. A soma da projeção horizontal de cada espécie em todas as UA correspondeu ao valor de cobertura absoluta da mesma na área. A cobertura relativa foi determinada dividindo a cobertura absoluta de cada espécie pela soma da cobertura absoluta de todas multiplicadas por 100. O registro de ocorrência de cada espécie nas UA foi utilizado para calcular a freqüência das mesmas na área.

As espécies foram identificadas por meio de literatura, exame de especialistas e comparação com exsicatas do herbário da Universidade de Brasília (UB) e da Reserva Ecológica do Instituto Brasileiro de Geografia e Estatística (IBGE). Os exemplares férteis
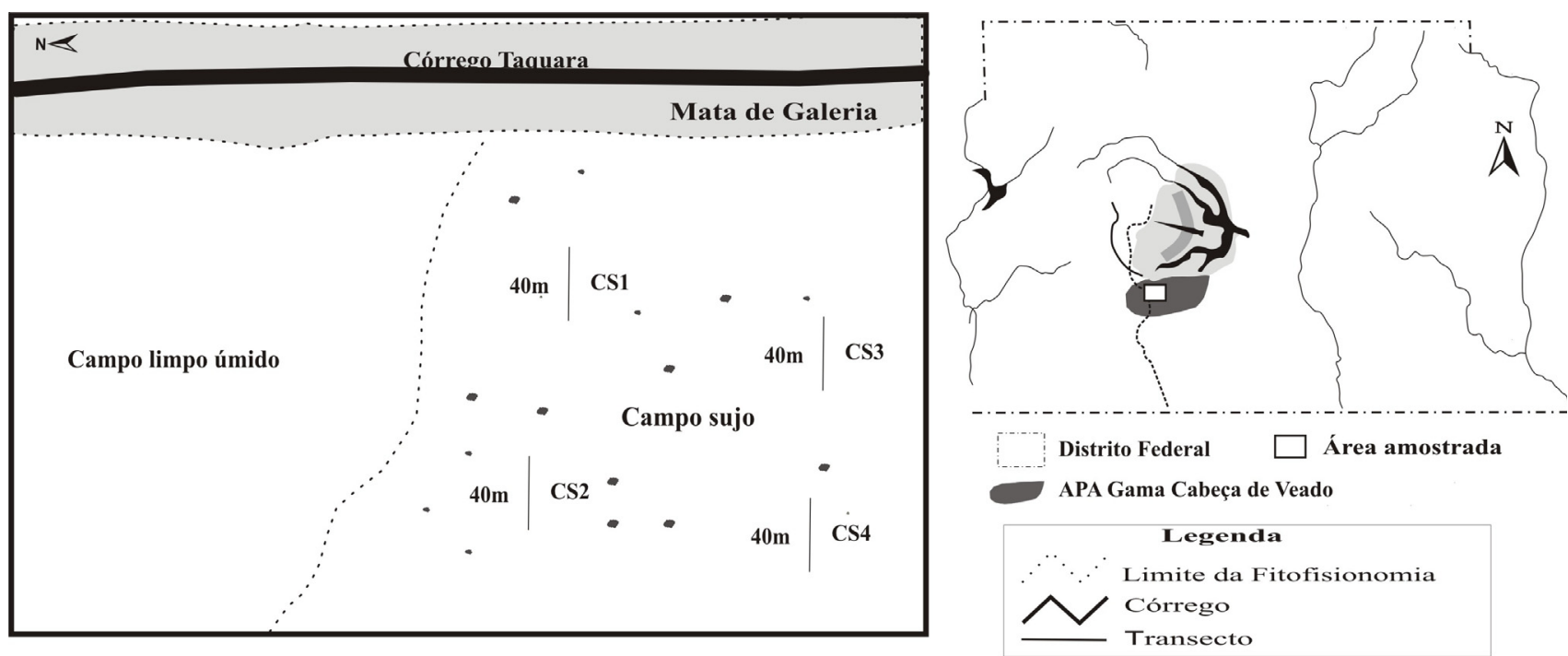

Figura 1. Esquema de disposição das linhas de amostragem no campo sujo na Fazenda Água Limpa, Brasília, DF. 
coletados foram herborizados de acordo com os procedimentos usuais e encontram-se depositados nos herbários citados. As espécies foram classificadas em famílias de acordo com o sistema do Angiosperm Phylogeny Group II (APG II, 2003).

Similaridade e diversidade - Para avaliar a diversidade florística da comunidade amostrada foi realizada uma adaptação do índice de diversidade de Shannon na base e (H'), utilizando-se ao invés do número de indivíduos os valores de cobertura dos cinco períodos de amostragem. Esse índice é baseado na teoria da informação, onde se assume que a diversidade, ou informação em um sistema natural pode ser medida de um modo similar à informação contida em um código ou mensagem. O índice de Shannon considera a abundância proporcional de espécies em uma amostra e, para o seu cálculo em geral utiliza-se a proporção de indivíduos por espécie (Magurran 1988). A abundância pode ser avaliada pelo número de indivíduos e por outras medidas de ocupação do espaço pelas plantas, como a freqüência e a cobertura (Kent \& Coker 1992). Neste caso, optou-se pelo uso da proporção de cobertura de espécie como uma medida de abundância, pois para o estrato herbáceo subarbustivo a definição de indivíduo é difícil, uma vez que rebrotos radiculares (rametes) de um mesmo indivíduo são comuns.

$$
H^{\prime}=-\sum_{i=1}^{n} P i \operatorname{Ln} P i
$$

onde: $p i$ é a proporção de cobertura de cada espécie $(p i=\mathrm{ni} / \mathrm{N}), \mathrm{ni}=$ cobertura da espécie $i$ e $\mathrm{N}=$ soma da cobertura de todas as espécies encontradas na área.

A similaridade entre as linhas e entre os diferentes períodos de amostragens foi avaliada pelo índice de similaridade qualitativo de Sørensen (Müller-Dombois \& Ellenberg 1974), e pelo quantitativo de Czekanowski, utilizando-se os valores de cobertura das espécies nas linhas. Esses índices foram calculados utilizando-se o programa MVSP (Kovach 1993).

A ocorrência ou não das espécies nos diferentes períodos de inventário também foi comparada ao registro ou não das mesmas nos levantamentos florísticos quinzenais realizados na área por Munhoz \& Felfili (2005), durante o ano da realização deste estudo.

Para a classificação da vegetação foi utilizado o método TWINSPAN - "Two-Way Indicador Species Analysis" (Hill 1979). Esse método resume os dados através da construção de uma tabela dicotômica que reúne as amostras e as espécies mais similares em grupos (Gauch 1982). Os padrões de distribuição das espécies obtidos através desse método podem ser relacionados a fatores ambientais verificados no campo (Kent \& Coker 1992).

\section{Resultados}

As espécies amostradas na área ao longo do período de estudo estão listadas na Tab. 1. Foram relacionadas 163 espécies, incluídas em 78 gêneros e 39 famílias, sendo que $35,9 \%$ das famílias e $72,2 \%$ dos gêneros foram representados por apenas uma espécie. As famílias com maior número de espécies foram Poaceae (25), Asteraceae (22), Fabaceae (18), Rubiaceae (11), Lamiaceae (nove) e Myrtaceae (nove), somando 57,67\% das espécies amostradas. A diversidade do campo sujo, nos cinco períodos de amostragem, segundo o índice de Shannon variou de 3,0 a 3,2 nats cobertura ${ }^{-1}$.

As famílias com maiores porcentagens de cobertura foram Poaceae, Myrtaceae, Asteraceae, Fabaceae e Euphorbiaceae (Fig. 2). Dessas famílias somente Poaceae apresentou cobertura relativa maior que freqüência relativa. As dez espécies com maior cobertura e freqüência relativa somaram $62,9 \%$ e $46,3 \%$ desses valores na área, respectivamente (Fig. 3). Cinco dessas espécies pertencem à família Poaceae e juntas representam $31,8 \%$ da freqüência relativa e $53,5 \%$ da cobertura relativa, com destaque para Echinolaena inflexa, Arthropogon villosus e Axonopus brasiliensis.

Andropogon leucostachyus, Arthropogon villosus, Baccharis humilis, Echinolaena inflexa e Leptocoryphium lanatum estiveram entre as dez principais espécies em porcentagem de cobertura em todos os períodos de amostragem, ocorrendo apenas uma alteração nas posições entre os períodos (Tab. 1).

Houve uma variação no número de espécies nos períodos de amostragem. Em novembro/1999 foram encontradas 106 espécies, e no ano de 2000, 128 em abril, 113 em julho, 114 em outubro e 128 em dezembro (Tab. 1). Embora tenha sido observada uma diferença no número de espécies entre os períodos de estudo, a similaridade florística no campo sujo entre as cinco amostragens foi alta para os coeficientes Sørensen e Czekanowski (Tab. 2). A variação temporal no registro das espécies nos levantamentos fitossociológicos levou à formação de 10 grupos de espécies reunidas por período de ocorrência (Tab. 1). O grupo 1 compreende as espécies inventariadas nos cinco levantamentos fitossociológicos, que representam $44,8 \%$ do total de espécies. 
Tabela 1. Freqüência relativa (FR) (\%) e cobertura relativa (CR) (\%) das espécies da flora herbáceo-subarbustiva de campo sujo, amostradas na Fazenda Água Limpa, Brasília, DF, em cinco períodos de amostragem distribuídos ao longo de um ano. As espécies foram agrupadas por período de ocorrência, (1) ocorreram o ano todo; (2) somente amostradas a partir de abril; (3) não ocorreram na seca; (4) ocorreram por um curto período, somente após o fogo; (5) ocorreram por um curto período, somente em abril ou em abril e na estação seca ou na seca e em outubro; (6) ocorreram por um curto período, somente na estação seca; (7) registradas predominantemente de novembro de 1999 à julho de 2000; (8) ocorreram por um curto período, somente 12 meses após o fogo; (9) não foram encontradas no final da estação chuvosa, na estação seca e algumas no início da estação chuvosa e (10) ocorreram por curtos períodos, em diferentes épocas nas estações seca e chuvosa. Negrito = dez principais espécies com maiores CR por período.

\begin{tabular}{|c|c|c|c|c|c|c|c|c|c|c|c|}
\hline \multicolumn{2}{|c|}{ Grupo/Família/Espécie } & \multicolumn{2}{|c|}{ Novembro/1999 } & \multicolumn{2}{|c|}{ Abril/2000 } & \multicolumn{2}{|c|}{ Julho/2000 } & \multicolumn{2}{|c|}{ Outubro/2000 } & \multicolumn{2}{|c|}{ Dezembro/2000 } \\
\hline \multirow[t]{3}{*}{1} & ACANTHACEAE & & & & & & & & & & \\
\hline & Justicia pycnophylla Lindau & 0,081 & 0,021 & 0,673 & 0,253 & 0,686 & 0,104 & 0,625 & 0,203 & 1,192 & 0,519 \\
\hline & Ruellia dissitifolia (Nees) Hiern & 0,645 & 0,472 & 0,741 & 0,816 & 0,857 & 0,557 & 0,625 & 0,381 & 0,753 & 0,395 \\
\hline \multirow[t]{2}{*}{1} & APIACEAE & & & & & & & & & & \\
\hline & $\begin{array}{l}\text { Eryngium juncifolium (Urban) } \\
\text { Mathias \& Constance }\end{array}$ & 0,725 & 0,430 & 0,943 & 0,787 & 1,885 & 1,114 & 0,972 & 0,563 & 1,066 & 0,738 \\
\hline \multirow[t]{9}{*}{1} & ASTERACEAE & & & & & & & & & & \\
\hline & Apopyros warmingii (Baker) G.L. Nesom & 0,161 & 0,175 & 0,067 & 0,099 & 0,086 & 0,043 & 0,069 & 0,040 & 0,063 & 0,067 \\
\hline & Aspilia foliacea (Spreng.) Baker & 1,289 & 0,710 & 0,875 & 0,520 & 0,771 & 0,282 & 0,903 & 0,331 & 0,439 & 0,188 \\
\hline & Baccharis humilis Sch. Bip. ex Baker & 3,062 & 2,038 & 3,098 & 2,767 & 3,685 & 2,349 & 3,958 & 2,263 & 3,701 & 2,533 \\
\hline & Calea platylepis Sch. Bip. ex Baker & 0,886 & 0,568 & 1,347 & 0,721 & 0,857 & 0,313 & 0,625 & 0,211 & 0,816 & 0,414 \\
\hline & $\begin{array}{l}\text { Lessingianthus bardanoides (Less.) } \\
\text { H. Rob. }\end{array}$ & 0,645 & 0,589 & 0,673 & 0,604 & 0,771 & 0,410 & 0,764 & 0,792 & 0,502 & 0,315 \\
\hline & Riencourtia oblongifolia Gardner & 0,161 & 0,054 & 0,337 & 0,187 & 0,343 & 0,089 & 0,278 & 0,091 & 0,502 & 0,130 \\
\hline & $\begin{array}{l}\text { Stenocephamum megapotamicum } \\
\text { (Spreng.) Sch. Bip. }\end{array}$ & 0,403 & 0,100 & 0,337 & 0,256 & 0,428 & 0,252 & 0,208 & 0,080 & 0,251 & 0,175 \\
\hline & Viguiera robusta Gardner & 0,725 & 0,622 & 0,741 & 0,351 & 1,714 & 0,878 & 0,972 & 0,694 & 0,816 & 0,458 \\
\hline \multirow[t]{2}{*}{1} & BIGNONIACEAE & & & & & & & & & & \\
\hline & $\begin{array}{l}\text { Anemopaegma arvense (Vell.) Stellfeld } \\
\text { ex de Souza }\end{array}$ & 0,081 & 0,038 & 0,067 & 0,018 & 0,171 & 0,023 & 0,069 & 0,022 & 0,063 & 0,019 \\
\hline \multirow[t]{2}{*}{1} & CHRYSOBALANACEAE & & & & & & & & & & \\
\hline & Parinari obtusifolia Hook. f. & 0,242 & 0,472 & 0,269 & 0,337 & 0,343 & 0,414 & 0,278 & 0,429 & 0,251 & 0,325 \\
\hline \multirow{2}{*}{1} & Meisn. & 0,483 & 0,138 & 0,337 & 0,088 & 0,086 & 0,023 & 0,556 & 0,120 & 0,502 & 0,140 \\
\hline & I. procurrens Meisn. & 1,370 & 0,363 & 0,875 & 0,183 & 0,086 & 0,004 & 0,417 & 0,131 & 0,627 & 0,175 \\
\hline \multirow[t]{4}{*}{1} & CYPERACEAE & & & & & & & & & & \\
\hline & $\begin{array}{l}\text { Bulbostylis junciformis (Kunth) } \\
\text { C.B. Clarke }\end{array}$ & 0,967 & 0,464 & 0,067 & 0,037 & 0,686 & 0,368 & 0,625 & 0,480 & 1,129 & 0,821 \\
\hline & B. paradoxa (Spreng.) Lindm. & 0,081 & 0,058 & 0,067 & 0,029 & 0,086 & 0,023 & 9 & 54 & 0,125 & 0,083 \\
\hline & $\begin{array}{l}\text { Rhynchospora aff. consanguinea } \\
\text { (Kunth) Boeck. }\end{array}$ & 0,806 & 0,230 & 1,010 & 0,666 & 0,171 & 0,054 & 0,347 & 0,160 & 0,816 & 0,341 \\
\hline \multirow[t]{2}{*}{1} & ERIOCAULACEAE & & & & & & & & & & \\
\hline & Paepalanthus speciosus Gardner & 0,161 & 0,071 & 0,471 & 0,674 & 0,343 & 0,213 & 0,278 & 0,171 & 0,251 & 0,181 \\
\hline \multirow[t]{2}{*}{1} & ERYTHROXYLACEAE & & & & & & & & & & \\
\hline & Erythroxylum deciduum A. St.-Hil & 2,256 & 0,911 & 1,886 & 1,058 & 1,200 & 0,693 & 2,431 & 1,108 & 2,509 & 0,961 \\
\hline \multirow[t]{4}{*}{1} & EUPHORBIACEAE & & & & & & & & & & \\
\hline & tisyphiliticus Mart. & 3,143 & 2,168 & 2,828 & 2,068 & 0,343 & 0,089 & 2,847 & 1,431 & 3,262 & 1,623 \\
\hline & C. campestris A. St.-Hil. & 0,483 & 0,263 & 0,471 & 0,168 & 0,257 & 0,085 & 0,764 & 0,222 & 0,439 & 0,181 \\
\hline & C. goyazensis Müll. Arg. & 0,967 & 0,430 & 1,077 & 0,483 & 0,943 & 0,275 & 1,042 & 0,668 & 1,004 & 0,541 \\
\hline \multirow[t]{2}{*}{1} & EUPHORBIACEAE & & & & & & & & & & \\
\hline & Dalechampia caperonioides Baill. & 0,725 & 0,677 & 0,943 & 0,974 & 1,200 & 0,774 & 1,111 & 0,785 & 1,192 & 0,668 \\
\hline \multirow[t]{6}{*}{1} & FABACEAE & & & & & & & & & & \\
\hline & Aescchynomene selloi Vogel & 0,483 & 0,192 & 0,943 & 0,392 & 0,086 & 0,023 & 0,694 & 0,262 & 1,066 & 0,525 \\
\hline & Andira humilis Mart. ex Benth. & 0,081 & 0,071 & 0,067 & 0,055 & 0,086 & 0,043 & 0,069 & 0,178 & 0,063 & 0,140 \\
\hline & $\begin{array}{l}\text { Chamaecrista pohliana (Benth.) H.S. } \\
\text { Irwin \& Barneby }\end{array}$ & 0,483 & 0,380 & 0,404 & 0,458 & 0,428 & 0,282 & 0,417 & 0,134 & 0,439 & 0,153 \\
\hline & Clitoria guianensis (Aubl.) Benth. & 0,967 & 0,426 & 1,145 & 0,589 & 0,257 & 0,066 & & 0,378 & 1,694 & 0,735 \\
\hline & Galactia grewiaefolia (Benth.) Taub. & 0,161 & 0,092 & 0,269 & 0,146 & 0,171 & 0,062 & 0,417 & 0,240 & 0,439 & 0,207 \\
\hline
\end{tabular}


Tabela 1 (continuação)

Grupo/Família/Espécie

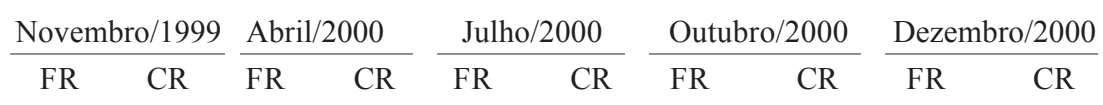

1 FABACEAE

Mimosa lanuginosa Glaz. ex Burkart

Mimosa nuda Benth.

Mimosa setosa Benth.

1 LAMIACEAE

Eriope complicata Mart. ex Benth.

Eriope crassipes Benth.

Hyptis nudicaulis Benth.

1 LYTHRACEAE

Cuphea linarioides Cham. \& Schltdl.

Diplusodon villosus Pohl

1 MALPIGHIACEAE

Byrsonima rigida A. Juss.

$\begin{array}{lll}0,886 & 0,668 & 0,741\end{array}$

$\begin{array}{lll}\mathbf{1 , 7 7 3} & \mathbf{2 , 9 4 9} & \mathbf{1 , 8 1 8}\end{array}$

0,245

0,771

0,325

1,724

0,343

0,062

0,694

0,418

0,565

$0,222 \quad 0,753$

0,274

$\begin{array}{llll}1,128 & 0,434 & 0,875 & 1,054\end{array}$

0,943

$1,209 \quad 0,414 \quad 0,943$

0,454

0,086

0,673

1,806

1,511

1,757

0,178

$\begin{array}{lll}0,161 & 0,088 & 0,539\end{array}$

0,253

0,428

1,042

0,647

0,941

1,664

$\begin{array}{llll}0,564 & 0,063 & 0,673\end{array}$

0,157

$\begin{array}{lll}0,161 & 0,042 & 0,269\end{array}$

0,428

0,027

0,327

0,690

0,395

$\begin{array}{lll}0,645 & 0,259 & 1,145\end{array}$

0,055

0,171

, 108

0,625

0,200

0,690

0,264

Byrsonima subterranea Brade \& Markgr.

Heteropterys campestris A. Juss.

$\begin{array}{lll}0,161 & 0,146 & 0,202\end{array}$

0,494

0,257

$\begin{array}{llll}0,242 & 0,380 & 0,539\end{array}$

0,190

0,257

$0,043 \quad 1,042$

0,138

0,941

0,309

Peixotoa goiana C.E. Anderson

$0,886 \quad 1,316 \quad 0,337$

0,454

0,514

0,081

0,208

0,007

0,063

0,220

1 MALVACEAE

Byttneria scalpellata Pohl

$\begin{array}{lll}0,322 & 0,138 & 0,269\end{array}$

0,143

0,257

0,170

0,625

0,389

0,816

$0,134 \quad 0,188$

$0,454 \quad 0,502$

0,003

Peltaea lasiantha Krapov. \& Cristóbal

$0,242 \quad 0,050 \quad 0,539$

0,171

$0,066 \quad 0,208$

0,193

0,188

0,306

0,124

0,401

MELASTOMATACEAE

Tibouchina aegopogon (Naudin) Cogn.

$0,161 \quad 0,125 \quad 0,202$

0,150

0,171

0,188

0,134

MYRTACEAE

Campomanesia pubescens (DC.) O. Berg

Campomanesia xanthocarpa O. Berg

Eugenia cristaensis O. Berg

Eugenia myrcianthes Nied.

Myrcia linearifolia Cambess.

Myrcia torta DC.

Myrciaria herbacea $\mathrm{O}$. Berg

1 OCHNACEAE

Ouratea floribunda Engl.

1 OXALIDACEAE

Oxalis densifolia Mart. \& Zucc.

1 POACEAE

Andropogon leucostachyus Kunth

Andropogon selloanus (Hack.) Hack.

Arthropogon villosus Nees

$\mathbf{4 , 3 5 1} \quad \mathbf{3 , 0 2 4} \quad \mathbf{4 , 5 7 9}$

$\begin{array}{llll}0,886 & 0,518 & 0,404\end{array}$

0,179

$0,171 \quad 0,054$

0,076

0,376

0,134

$\begin{array}{lll}1,289 & 0,652 & 1,212\end{array}$

3,686

$0,171 \quad 0,058 \quad 0,139$

0,091

0,188

0,115

$1,048 \quad 0,338 \quad 0,741$

0,293

2,742

0,712

$\mathbf{4 , 7 2 2}$

3,927

4,642

3,609

$0,645 \quad 0,338 \quad 0,606$

0,670

0,257

0,163

0,278

0,142

0,125

0,083

$\begin{array}{lll}0,081 & 0,008 & 0,067\end{array}$

0,465

0,857

$0,720 \quad 1,389$

0,748

1,945

0,649

0,276

0,376

0,162

$1,853 \quad 1,145 \quad \mathbf{2 , 2 2 2}$

$0,007-0,257 \quad 0,093$

0,139

0,690

0,636

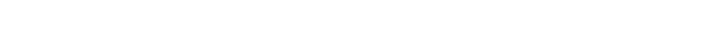

1,777

0,125

0,038

$\begin{array}{lllllll}0,322 & 0,393 & 0,337 & 0,333 & 0,343 & 0,399 & 0,417\end{array}$

0,258

0,376

0,274

$0,081 \quad 0,008 \quad 0,067 \quad 0,015$

$0,343 \quad 0,046$

0,347

0,084

0,314

0,089

$\mathbf{4 , 6 7 4} \quad \mathbf{7 , 4 1 0} \quad \mathbf{4 , 6 4 6} \quad \mathbf{1 0 , 0 3 7}$

$5,398 \quad 10,572$

5,139

$\begin{array}{llll}0,645 & 0,685 & 2,020 & 1,512\end{array}$

$2,057 \quad 2,016$

1,319

12,454

6,023

15,301

$\mathbf{5 , 8 0 2} \quad \mathbf{6 , 9 5 1} \quad \mathbf{1 1 , 1 7 8} \quad \mathbf{1 8 , 6 8 0}$

$\mathbf{9 , 5 1 2} \quad 9,492$

1,293

1,129

1,365

$\mathbf{8 , 6 2 2} \mathbf{1 2 , 2 7 2} \quad 1,279 \quad 1,395$

$\mathbf{6 , 2 5 5} \quad 12,317$

$6,806 \quad 6,983$

$\mathbf{5 , 0 8 2}$

Axonopus brasiliensis (Spreng.) Kuhlm.

Axonopus marginatus (Trin.) Chase

Echinolaena inflexa (Poir.) Chase

$\begin{array}{llll}\mathbf{1 1 , 2 0 1} & \mathbf{2 4 , 0 5 6} & 1,886 & 0,919\end{array}$

$6,319 \quad 17,155$

6,964

5,461

$\begin{array}{llllllllll}4,915 & 6,023 & 9,562 & 14,983 & 12,254 & 21,925 & 10,208\end{array}$

2,470

3,764

19,409

$\begin{array}{lllllll}0,725 & 0,998 & 0,741 & 1,212 & 1,028 & 0,983 & 0,764\end{array}$

15,001

9,159

2,785

0,916

0,627

13,299

$\begin{array}{lllllll}1,128 & 1,571 & \mathbf{2 , 2 2 2} & \mathbf{5 , 7 2 5} & \mathbf{2 , 7 4 2} & \mathbf{6 , 2 3 0} & \mathbf{2 , 1 5 3}\end{array}$

4,999

$\mathbf{1 , 5 0 6}$

1,451

$\begin{array}{lllllll}0,403 & 0,752 & 1,077 & 1,856 & 1,371 & 1,853 & 1,111\end{array}$

1,915

2,509

2,772

Panicum olyroides Kunth

Paspalum imbricatum Filg.

$0,081 \quad 0,134 \quad 0,067 \quad 0,165$

$0,086 \quad 0,232$

0,069

0,211

0,063

3,491

$\begin{array}{llll}0,725 & 0,969 & 0,943 & 1,486\end{array}$

$\begin{array}{lll}1,457 & 2,086 & \mathbf{1 , 4 5 8}\end{array}$

2,452

0,941

0,156 ex Flüeggé

1 RHAMNACEAE

Crumenaria chorethroides Mart. ex Reissek

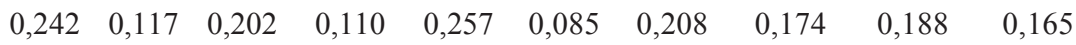

1 RUBIACEAE

Borreria poaya (A. St.-Hil.) DC.

Palicourea coriacea (Cham.) K. Schum.

Tocoyena formosa (Cham. \& Schltdl.) K. Schum.

$0,161 \quad 0,021 \quad 0,337 \quad 0,095$

$\begin{array}{lll}0,428 & 0,085 & 0,347\end{array}$

$0,102 \quad 0,439 \quad 0,178$

$\begin{array}{llllllllll}0,403 & 0,159 & 0,539 & 0,267 & 0,257 & 0,085 & 0,486 & 0,145 & 0,439 & 0,153 \\ 0,161 & 0,088 & 0,269 & 0,212 & 0,086 & 0,008 & 0,278 & 0,174 & 0,251 & 0,200\end{array}$ 
Tabela 1 (continuação)

\begin{tabular}{|c|c|c|c|c|c|c|c|c|c|c|c|}
\hline \multicolumn{2}{|c|}{ Grupo/Família/Espécie } & \multicolumn{2}{|c|}{ Novembro/1999 } & \multicolumn{2}{|c|}{ Abril/2000 } & \multicolumn{2}{|c|}{ Julho/2000 } & \multicolumn{2}{|c|}{ Outubro/2000 } & \multicolumn{2}{|c|}{ Dezembro/2000 } \\
\hline & & FR & $\mathrm{CR}$ & FR & $\mathrm{CR}$ & FR & CR & FR & $\mathrm{CR}$ & FR & $\mathrm{CR}$ \\
\hline 1 & SALICACEAE & & & & & & & & & & \\
\hline 1 & $\begin{array}{l}\text { Casearia sylvestris Sw. } \\
\text { SIMARUBACEAE }\end{array}$ & 0,403 & 0,146 & 0,673 & 0,403 & 0,514 & 0,197 & 0,486 & 0,236 & 0,816 & 0,350 \\
\hline 1 & $\begin{array}{l}\text { Simaba suffruticosa Engl. } \\
\text { SMILACACEAE }\end{array}$ & 1,612 & 0,977 & 1,481 & 1,124 & 2,314 & 1,153 & 1,528 & 0,807 & 1,694 & 0,592 \\
\hline 1 & $\begin{array}{l}\text { Smilax goyazana A. DC. } \\
\text { Solo descoberto }\end{array}$ & 0,322 & 0,209 & 0,404 & 0,139 & 0,171 & 0,046 & 0,278 & 0,105 & 0,251 & 0,076 \\
\hline & Solo descoberto & 8,300 & 6,441 & 5,859 & 3,463 & 6,341 & 4,299 & 4,444 & 2,794 & 2,070 & 0,945 \\
\hline 1 & TURNERACEAE & & & & & & & & & & \\
\hline 1 & $\begin{array}{l}\text { Piriqueta sidifolia (Camb.) Urb. } \\
\text { VERBENACEAE }\end{array}$ & 0,806 & 0,213 & 0,606 & 0,201 & 0,171 & 0,027 & 0,417 & 0,102 & 0,941 & 0,251 \\
\hline 2 & $\begin{array}{l}\text { Stachytarpheta gesnerioides Cham. } \\
\text { ASTERACEAE }\end{array}$ & 0,161 & 0,071 & 0,269 & 0,150 & 0,257 & 0,019 & 0,208 & 0,065 & 0,188 & 0,165 \\
\hline & Aspilia jolyana G.M. Barroso & - & - & 0,135 & 0,048 & 0,086 & 0,039 & 0,139 & 0,044 & 0,125 & 0,035 \\
\hline & Asteraceae 1 (CM-1059) & - & - & 0,202 & 0,055 & 0,257 & 0,224 & 0,069 & 0,040 & 0 & 0,041 \\
\hline & Porophyllum lanceolatum DC. & - & - & 0,202 & 0,051 & 0,171 & 0,108 & 0,069 & 0,033 & 0,188 & 0,045 \\
\hline & Stevia heptachaeta DC. & - & - & 0,337 & 0,059 & 0,343 & 0,124 & 0,208 & 0,029 & 0,063 & 0,013 \\
\hline 2 & CYPERACEAE & & & & & & & & & & \\
\hline 2 & $\begin{array}{l}\text { Scleria hirtella Sw. } \\
\text { EUPHORBIACEAE }\end{array}$ & - & - & 0,202 & 0,029 & 0,171 & 0,015 & 0,069 & 0,015 & 0,251 & 0,054 \\
\hline & $\begin{array}{l}\text { Chamaesyce coecorum (Mart. ex Boiss.) } \\
\text { Croyzat }\end{array}$ & - & - & 0,067 & 0,011 & 0,171 & 0,058 & 0,069 & 0,022 & 0,063 & 0,048 \\
\hline 2 & FABACEAE & & & & & & & & & & \\
\hline & $\begin{array}{l}\text { Chamaecrista cathartica (Mart.) Irwin } \\
\text { \& Barneby }\end{array}$ & - & - & 0,135 & 0,051 & 0,086 & 0,027 & 0,069 & 0,018 & 0,063 & 0,016 \\
\hline & MALVACEAE & & & & & & & & & & \\
\hline 2 & $\begin{array}{l}\text { Pavonia rosa-campestris A. St.-Hil. } \\
\text { MELASTOMATACEAE }\end{array}$ & - & - & 0,135 & 0,081 & 0,086 & 0,008 & 0,208 & 0,040 & 0,376 & 0,086 \\
\hline 2 & $\begin{array}{l}\text { Cambessedesia espora DC. } \\
\text { POACEAE }\end{array}$ & - & - & 0,202 & 0,029 & 0,343 & 0,116 & 0,278 & 0,051 & 0,251 & 0,019 \\
\hline & Aristida ripar & - & - & 0,067 & 0,044 & 0,171 & 0,186 & 6 & 0,334 & 01 & 0,115 \\
\hline & Aristida setifolia Kunth & - & - & 0,337 & 0,194 & 0,943 & 0,348 & 0,139 & 0,018 & 0,0 & 0,025 \\
\hline & ureus P. Beauv. & - & - & 0,135 & 0,055 & 0,171 & 0,066 & 0,069 & 0,007 & 0,063 & 0,013 \\
\hline & Paspalum gardnerianum Nees & - & - & 0,337 & 0,172 & 1,799 & 1,176 & 0,486 & 0,174 & 0,251 & 0,242 \\
\hline 2 & $\begin{array}{l}\text { Paspalum reduncum Nees ex Steud. } \\
\text { POLYGALACEAE }\end{array}$ & - & - & 1,414 & 1,629 & 2,913 & 3,943 & 1,389 & 1,322 & 0,753 & 0,897 \\
\hline 2 & $\begin{array}{l}\text { Monnina exaltata A.W. Benn. } \\
\text { TURNERACEAE }\end{array}$ & - & - & 0,067 & 0,018 & 0,257 & 0,070 & 0,278 & 0,080 & 0,314 & 0,080 \\
\hline 2 & $\begin{array}{l}\text { Turnera oblongifolia Cambess. } \\
\text { VERBENACEAE }\end{array}$ & - & - & 0,135 & 0,026 & 0,086 & 0,008 & 0,278 & 0,022 & 0,314 & 0,016 \\
\hline 2 & $\begin{array}{l}\text { Amazonia hirta } \text { Benth. } \\
\text { XYRIDACEAE }\end{array}$ & - & - & 0,067 & 0,062 & 0,086 & 0,012 & 0,069 & 0,011 & 0,063 & 0,038 \\
\hline 3 & $\begin{array}{l}\text { Xyris schizachne Mart. } \\
\text { ASTERACEAE }\end{array}$ & - & - & 0,337 & 0,106 & 0,428 & 0,135 & 0,208 & 0,149 & 0,314 & 0,150 \\
\hline & Calea $\xi$ & 0,322 & 0,426 & & & - & - & & & & 0,165 \\
\hline 3 & $\begin{array}{l}\text { Lessingianthus simplex (Less.) H. Rob. } \\
\text { FABACEAE }\end{array}$ & 0,564 & 0,209 & 0,404 & 0,245 & - & - & 0,208 & 0,065 & 0,565 & 0,267 \\
\hline & Bauhinia sp.1 & 0,081 & 0,046 & 0,067 & 0,040 & - & - & & 0, & & 0,048 \\
\hline & Mimosa xanthocentra Mart. & 0,161 & 0,188 & 0,135 & 0,168 & - & - & 0,069 & 0,011 & 0,063 & 0,051 \\
\hline 3 & LAMIACEAE & & & & & & & & & & \\
\hline 3 & $\begin{array}{l}\text { Marsypianthes montana Benth. } \\
\text { LYTHRACEAE }\end{array}$ & 0,161 & 0,075 & 0,067 & 0,015 & 0,086 & 0,027 & - & - & 0,125 & 0,073 \\
\hline 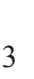 & $\begin{array}{l}\text { Cuphea spermacoce A. St.-Hil. } \\
\text { OXALIDACEAE }\end{array}$ & 0,645 & 0,201 & 0,673 & 0,249 & - & - & 0,417 & 0,174 & 0,878 & 0,382 \\
\hline & Oxalis suborbiculata Lourteig & 0,564 & 0,088 & 0,404 & 0,077 & - & - & 0,694 & 0,134 & 0,439 & 0,086 \\
\hline
\end{tabular}


Tabela 1 (continuação)

Grupo/Família/Espécie

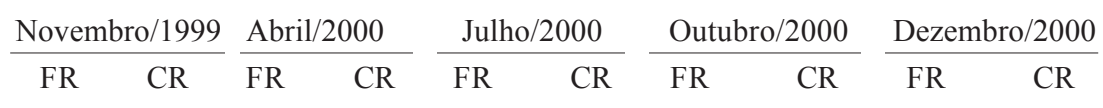

3 RUBIACEAE

Palicourea officinalis Mart.

3 SOLANACEAE

Solanum subumbellatum Vell.

4 ACANTHACEAE

Ruellia incompta (Nees) Lindau

4 ASTERACEAE

Bidens graveolens Mart.

Lessingianthus argyrophyllus (Less.)

H. Rob.

Viguiera bracteata Gardner

4 BORAGINACEAE

Cordia calocephala Cham.

4 CYPERACEAE

Bulbostylis hirtella (Schrad. ex Schult.) Nees ex Urb.

4 EUPHORBIACEAE

Euphorbia sp.

4 FABACEAE

Galactia peduncularis (Benth.) Taub.

4 POACEAE

Axonopus siccus (Ness.) Kunth.

4 POLYGALACEAE

Polygala tenuis DC.

4 RUBIACEAE

Borreria $\mathrm{sp.}$

Borreria tenella Cham. \& Schltdl.

5 FABACEAE

Mimosa albolanata Taub.

5 LAMIACEAE

Hypenia brachystachys (Pohl ex Benth.) Harley

Hyptis tenuifolia Epling.

5 MELASTOMATACEAE

Tibouchina gracilis (Bonpl.) Cogn.

5 MYRTACEAE

Eugenia bracteata Rich.

5 POACEAE

Panicum cyanescens Nees ex Trin.

Paspalum ellipticum Döll

Paspalum geminiflorum Steud.

5 RUBIACEAE

Staelia capitata K. Schum.

5 VERBENACEAE

Lippia martiana Schauer

6 CONVOLVULACEAE

Evolvulus lagopodioides Meisn.

6 CYPERACEAE

Bulbostylis sp.

6 MYRTACEAE

Myrcia hiemalis Cambess.

6 POACEAE

Paspalum polyphyllum Nees ex Trin.

Trachypogon spicatus (L.f.) Kuntze

6 POLYGALACEAE

Polygala aff. remota Benn.

\begin{tabular}{|c|c|c|c|c|c|c|c|c|c|}
\hline 0,081 & 0,050 & 0,067 & 0,022 & - & - & - & - & 0,125 & 0,032 \\
\hline 0,242 & 0,088 & 0,135 & 0,037 & - & - & 0,208 & 0,084 & 0,188 & 0,095 \\
\hline 0,242 & 0,054 & 0,067 & 0,044 & - & - & - & - & - & - \\
\hline 0,161 & 0,067 & 0,135 & 0,077 & - & - & - & - & - & - \\
\hline 0,081 & 0,046 & - & - & - & - & - & - & - & - \\
\hline 0,081 & 0,029 & 0,404 & 0,128 & - & - & - & - & - & - \\
\hline 0,081 & 0,033 & - & - & - & - & - & - & - & - \\
\hline 0,081 & 0,013 & 0,135 & 0,081 & - & - & - & - & - & - \\
\hline 0,242 & 0,063 & - & - & - & - & - & - & - & - \\
\hline 0,161 & 0,025 & - & - & - & - & - & - & - & - \\
\hline 0,081 & 0,058 & - & - & - & - & - & - & - & - \\
\hline 0,161 & 0,008 & - & - & - & - & - & - & - & - \\
\hline 0,322 & 0,104 & - & - & - & - & - & - & - & - \\
\hline 0,242 & 0,054 & - & - & - & - & - & - & - & - \\
\hline- & - & 0,067 & 0,007 & 0,086 & 0,012 & - & - & - & - \\
\hline- & - & 0,067 & 0,004 & - & - & - & - & - & - \\
\hline- & - & 0,067 & 0,007 & 0,171 & 0,066 & - & - & - & - \\
\hline- & - & 0,067 & 0,007 & - & - & - & - & - & - \\
\hline- & - & 0,067 & 0,059 & - & - & - & - & - & - \\
\hline- & - & 0,202 & 0,037 & - & - & - & - & - & - \\
\hline- & - & 0,135 & 0,029 & 0,171 & 0,093 & - & - & - & - \\
\hline- & - & 1,077 & 0,813 & 0,771 & 0,437 & 0,069 & 0,058 & - & - \\
\hline- & - & 0,067 & 0,004 & - & - & - & - & - & - \\
\hline- & - & 0,067 & 0,015 & - & - & - & - & - & - \\
\hline- & - & - & - & 0,086 & 0,008 & - & - & - & - \\
\hline- & - & - & - & 0,086 & 0,012 & 0,139 & 0,091 & 0,125 & 0,041 \\
\hline- & - & - & - & 0,086 & 0,023 & - & - & - & - \\
\hline- & - & - & - & 0,086 & 0,039 & - & - & - & - \\
\hline- & - & - & - & 0,171 & 0,070 & - & - & - & - \\
\hline- & - & - & - & 0,086 & 0,004 & - & - & - & - \\
\hline
\end{tabular}


Tabela 1 (continuação)

\begin{tabular}{|c|c|c|c|c|c|c|c|c|c|c|c|}
\hline \multicolumn{2}{|c|}{ Grupo/Família/Espécie } & \multicolumn{2}{|c|}{ Novembro/1999 } & \multicolumn{2}{|c|}{ Abril $/ 2000$} & \multicolumn{2}{|c|}{ Julho/2000 } & \multicolumn{2}{|c|}{ Outubro/2000 } & \multicolumn{2}{|c|}{ Dezembro/2000 } \\
\hline \multirow[t]{2}{*}{7} & ACANTHACEAE & & & & & & & & & & \\
\hline & $\begin{array}{l}\text { Justicia oncoides (Lindau) Wassh. } \\
\text { \& C. Ezcurra }\end{array}$ & 0,081 & 0,008 & 0,404 & 0,245 & 0,086 & 0,015 & - & - & - & - \\
\hline \multirow[t]{2}{*}{7} & APOCYNACEAE & & & & & & & & & & \\
\hline & $\begin{array}{l}\text { Oxypetalum erectum Mart. } \\
\text { ASTERACEAE }\end{array}$ & 0,161 & 0,075 & 0,135 & 0,073 & 0,086 & 0,035 & 0,069 & 0,065 & - & - \\
\hline 7 & Chresta sphaerocephala DC. & 0,081 & 0,084 & 0,067 & 0,234 & 0,171 & 0,464 & - & - & - & - \\
\hline 7 & $\begin{array}{l}\text { FABACEAE } \\
\text { Zornia virgata Moric. }\end{array}$ & 0,081 & 0,008 & 0,135 & 0,066 & 0,086 & 0,027 & - & - & - & - \\
\hline \multirow[t]{2}{*}{7} & LAMIACEAE & & & & & & & & & & \\
\hline & $\begin{array}{l}\text { Hyptis villosa Pohl ex Benth. } \\
\text { POACEAE }\end{array}$ & 0,081 & 0,033 & 0,135 & 0,084 & 0,086 & 0,015 & - & - & - & - \\
\hline 7 & $\begin{array}{l}\text { Andropogon bicornis } \mathrm{L} \text {. } \\
\text { APOCYNACEAE }\end{array}$ & 0,081 & 0,013 & 0,067 & 0,220 & 0,086 & 0,155 & 0,417 & 0,265 & - & - \\
\hline \multirow{2}{*}{8} & Ditassa sp. & - & - & - & - & - & - & - & - & 0,188 & 0,060 \\
\hline & $\begin{array}{l}\text { Macrosiphonia longiflora (Desf.) } \\
\text { Müll. Arg. }\end{array}$ & - & - & - & - & - & - & 0,069 & 0,007 & - & - \\
\hline \multirow[t]{5}{*}{8} & ASTERACEAE & & & & & & & & & & \\
\hline & Calea cuneifolia DC. & - & - & - & - & - & - & - & - & 0,125 & 0,057 \\
\hline & $\begin{array}{l}\text { Campouloclinum megacephalum } \\
\quad \text { (Mart. ex Baker) R.M. King. \& H. Rob. }\end{array}$ & - & - & - & - & - & - & - & - & 0,125 & 0,035 \\
\hline & Ichthyothere latifolia Baker & - & - & - & - & - & - & - & - & 0,188 & 0,041 \\
\hline & Wedelia bishopii H. Rob. & - & - & - & - & - & - & - & - & 0,063 & 0,019 \\
\hline \multirow[t]{2}{*}{8} & BIGNONIACEAE & & & & & & & & & & \\
\hline & $\begin{array}{l}\text { Jacaranda ulei Bureau \& K. Schum. } \\
\text { CONVOLVULACEAE }\end{array}$ & - & - & - & - & - & - & 0,069 & 0,025 & 0,063 & 0,022 \\
\hline 8 & $\begin{array}{l}\text { Ipomoea } \text { sp. } \\
\text { CYPERACEAE }\end{array}$ & - & - & - & - & - & - & 0,278 & 0,051 & 0,251 & 0,080 \\
\hline 8 & $\begin{array}{l}\text { Rhynchospora patuligluma C.B. } \\
\text { Clarke ex Lindm. }\end{array}$ & - & - & - & - & - & - & - & - & 0,125 & 0,019 \\
\hline \multirow[t]{2}{*}{8} & EUPHORBIACEAE & & & & & & & & & & \\
\hline & $\begin{array}{l}\text { Acalypha claussenii (Turcz.) Müll. Arg. } \\
\text { FABACEAE }\end{array}$ & - & - & - & - & - & - & - & - & 0,063 & 0,010 \\
\hline 8 & $\begin{array}{l}\text { Desmodium platycarpum Benth. } \\
\text { IRIDACEAE }\end{array}$ & - & - & - & - & - & - & - & - & 0,188 & 0,035 \\
\hline 8 & $\begin{array}{l}\text { Sisyrinchium restioides Spreng. } \\
\text { LAMIACEAE }\end{array}$ & - & - & - & - & - & - & 0,069 & 0,029 & 0,188 & 0,057 \\
\hline 8 & Rhabdocaulon denudatum (Benth.) Epling. & - & - & - & - & - & - & - & - & 0,063 & 0,022 \\
\hline \multirow[t]{2}{*}{8} & ORCHIDACEAE & & & & & & & & & & \\
\hline & Cleistes sp. & - & - & - & - & - & - & 0,069 & 0,004 & 0,063 & 0,003 \\
\hline \multirow[t]{2}{*}{8} & OROBANCHACEAE & & & & & & & & & & \\
\hline & Esterhazya splendida J.C. Mikan & - & - & - & - & - & - & - & - & 0,063 & 0,025 \\
\hline 8 & POACEAE & & & & & & & & & & \\
\hline & $\begin{array}{l}\text { Arundinella hispida (Humb., Bonpl. } \\
\text { ex Willd.) Kuntze }\end{array}$ & - & - & - & - & - & - & - & - & 0,063 & 0,035 \\
\hline 8 & RUBIACEAE & & & & & & & & & & \\
\hline 8 & $\begin{array}{l}\text { Galianthe ramosa E.L.Cabral } \\
\text { SOLANACEAE }\end{array}$ & - & - & - & - & - & - & - & - & 0,063 & 0,006 \\
\hline 9 & $\begin{array}{l}\text { Solanum americanum Mill. } \\
\text { CLUSIACEAE }\end{array}$ & - & - & - & - & - & - & - & - & 0,125 & 0,060 \\
\hline & Kielmeyera abdita Saddi & - & - & 0,067 & 0,037 & - & - & 0,069 & 0,051 & 0,063 & 0,067 \\
\hline 9 & FABACEAE & & & & & & & & & & \\
\hline & Bauhinia sp.2 & - & - & 0,067 & 0,033 & - & - & 0,069 & 0,018 & 0,063 & 0,016 \\
\hline 9 & $\begin{array}{l}\text { Stylosanthes guianensis (Aubl.) Sw. } \\
\text { MALPIGHIACEAE }\end{array}$ & - & - & 0,067 & 0,037 & - & - & 0,208 & 0,051 & 0,251 & 0,022 \\
\hline & Tetrapteryx ambigua (A. Juss.) Nied. & 0,564 & 0,163 & - & - & - & - & - & - & 0,063 & $\begin{array}{r}0,064 \\
\text { ontinua }\end{array}$ \\
\hline
\end{tabular}


Tabela 1 (continuação)

\begin{tabular}{|c|c|c|c|c|c|c|c|c|c|c|c|}
\hline \multirow{2}{*}{\multicolumn{2}{|c|}{ Grupo/Família/Espécie }} & \multicolumn{2}{|c|}{ Novembro/1999 } & \multicolumn{2}{|c|}{ Abril/2000 } & \multicolumn{2}{|c|}{ Julho/2000 } & \multicolumn{2}{|c|}{ Outubro/2000 } & \multicolumn{2}{|c|}{ Dezembro/2000 } \\
\hline & & FR & $\mathrm{CR}$ & FR & $\mathrm{CR}$ & FR & CR & FR & CR & FR & $\mathrm{CR}$ \\
\hline \multirow[t]{2}{*}{9} & MENISPERMACEAE & & & & & & & & & & \\
\hline & Cissampelos ovalifolia DC. & 0,081 & 0,038 & - & - & - & - & 0,069 & 0,040 & 0,063 & 0,006 \\
\hline \multirow[t]{2}{*}{9} & POACEAE & & & & & & & & & & \\
\hline & Tristachya leiostacchya Nees & 0,081 & 0,297 & - & - & 0,086 & 0,104 & 0,069 & 0,127 & 0,063 & 0,274 \\
\hline \multirow[t]{3}{*}{9} & RUBIACEAE & & & & & & & & & & \\
\hline & $\begin{array}{l}\text { Declieuxia cordigera Mart. \& Zucc. } \\
\text { ex Schult. \& Schult. f. var. cordigera }\end{array}$ & 0,161 & 0,142 & - & - & - & - & 0,069 & 0,018 & - & - \\
\hline & $\begin{array}{l}\text { Mitracarpus frigidus (Willd. ex Roem. } \\
\text { \& Schult.) Schum. }\end{array}$ & - & - & 0,067 & 0,011 & - & - & - & - & 0,251 & 0,099 \\
\hline \multirow[t]{2}{*}{10} & FABACEAE & & & & & & & & & & \\
\hline & $\begin{array}{l}\text { Mimosa gracilis Benth. } \\
\text { OROBANCHACEAE }\end{array}$ & 0,081 & 0,104 & - & - & 0,086 & 0,070 & - & - & - & - \\
\hline 10 & Buchnera rosea Kunth & - & - & 0,067 & 0,004 & 0,086 & 0,008 & - & - & 0,063 & 0,022 \\
\hline \multirow[t]{2}{*}{10} & RUBIACEAE & & & & & & & & & & \\
\hline & Richardia scabra L. & - & - & 0,135 & 0,037 & 0,086 & 0,008 & - & - & 0,063 & 0,038 \\
\hline \multicolumn{2}{|c|}{ Total de espécies } & \multicolumn{2}{|c|}{106} & \multicolumn{2}{|c|}{128} & \multicolumn{2}{|c|}{113} & \multicolumn{2}{|c|}{114} & \multicolumn{2}{|c|}{128} \\
\hline
\end{tabular}

Na primeira amostragem, realizada três meses após o fogo, foi encontrado o menor número de espécies (106) durante o período de estudo e a maior porcentagem de solo descoberto. Muitas espécies, como Andropogon leucostachyus, Arthropogon villosus, Echinolaena inflexa e Xyris schizachne, aumentaram as suas taxas de cobertura a partir do inventário de abril de 2000, com o distanciamento da ocorrência do fogo. Doze espécies foram registradas somente após o evento do fogo (grupo 4, Tab. 1), enquanto outras 18 (grupo 8, Tab. 1) somente foram amostradas nos inventários de outubro e

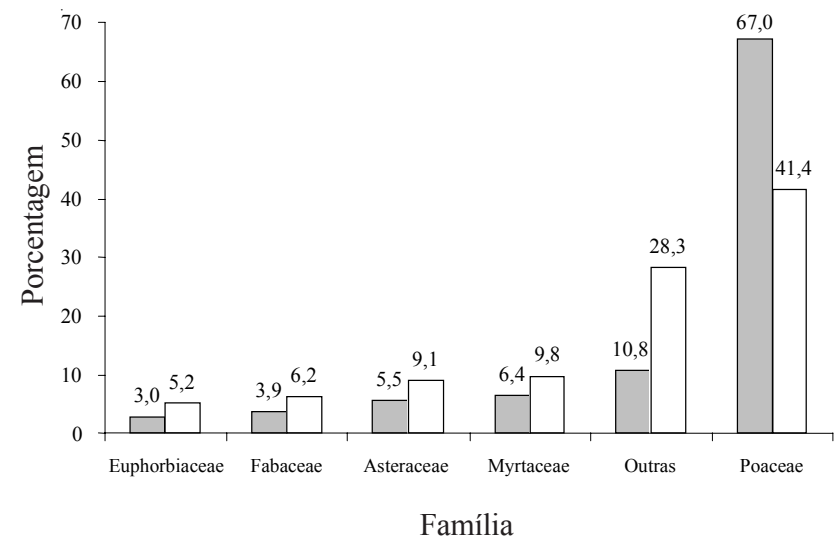

Figura 2. Distribuição em porcentagem de cobertura e freqüência relativa, média dos cinco períodos de amostragem, por família para a flora herbáceo-subarbustiva de uma área de campo sujo na Fazenda Água Limpa, Brasília, DF. $\square=$ Cobertura relativa; $\square=$ Freqüência relativa. dezembro/2000, depois de 15 a 17 meses do fogo ocorrido na área.

O maior número de espécies (128) foi registrado em abril e dezembro de 2000, pois 18 espécies perenes (11,0\% do total), como Paspalum reduncum, Aristida riparia, Amazonia hirta, Axonopus aureus e Cambessedesia espora, foram inventariadas na área somente a partir de abril, após um intervalo maior da ocorrência do fogo (grupo 2, Tab. 1). Outras dez espécies $(6,1 \%)$ que ocorreram por um curto período, somente em abril ou em abril e na estação seca, também ocorreram nesse período (grupo 5, Tab. 1), entre elas:

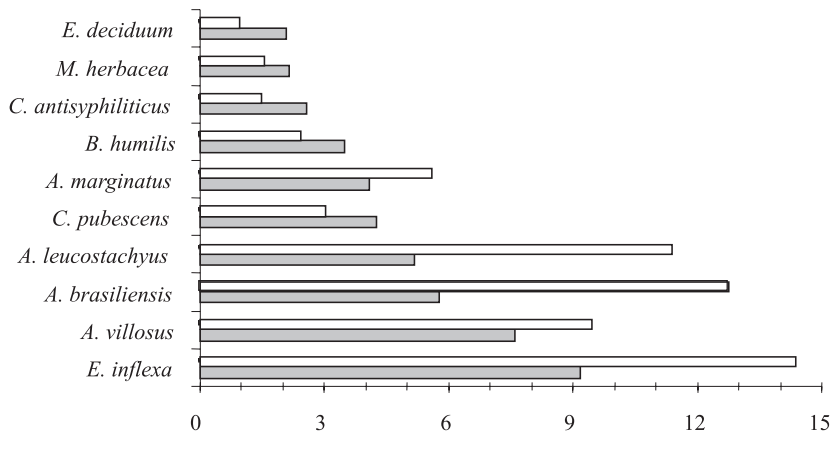

$(\%)$

Figura 3. As dez espécies com maior freqüência relativa e cobertura relativa, média dos cinco períodos de amostragem, para a flora herbáceo-subarbustiva de uma área de campo sujo na Fazenda Água Limpa, Brasília, DF. (Nomes das espécies, ver Tabela 1). $\square=$ Freqüência relativa; $\square=$ Cobertura relativa . 
Tabela 2. Índices de Similaridade de Sørensen (qualitativo, variando de 0 a 1) e de Czezanowski entre parênteses (quantitativo, dado em porcentagem) para a flora herbáceo-subarbustiva de campo sujo na Fazenda Água Limpa, Brasília, DF, em cinco períodos de amostragem distribuídos ao longo de um ano.

\begin{tabular}{lcccccc}
\hline & Novembro/1999 & Abril/2000 & Julho/2000 & Outubro/2000 & Dezembro/2000 \\
\hline Novembro/1999 & $1 \quad(100,00)$ & & & & & \\
Abril/2000 & $0,79(79,09)$ & $1 \quad(100,00)$ & & & & \\
Julho/2000 & $0,76(72,32)$ & $0,87(80,53)$ & $1 \quad(100,00)$ & & & \\
Outubro/2000 & $0,78(79,67)$ & $0,87(85,61)$ & $0,85(82,09)$ & 1 & $(100,00)$ & \\
Dezembro/2000 & $0,73(76,21)$ & $0,84(82,89)$ & $0,80(76,04)$ & $0,90(88,91)$ & $(100,00)$ \\
\hline
\end{tabular}

Eugenia bracteata, Hypenia brachystachys, Lippia martiana, Mitracarpus frigidus, Panicum cyanescens e Paspalum ellipticum.

Nove espécies não foram registradas apenas no inventário realizado no mês de julho, no auge da estação seca, pois perderam toda a parte aérea nesse período (grupo 3, Tab. 1). As espécies do grupo sete reduziram suas coberturas em julho e não ocorreram nos inventários de outubro e dezembro/2000. Enquanto algumas espécies, como Axonopus marginatus, Campomanesia pubescens e Mimosa setosa, diminuíram sua cobertura vegetativa e outras desapareceram na seca, espécies como Andropogon selloanus, Echinolaena inflexa e Eryngium juncifolium aumentaram as suas taxas de cobertura, e outras espécies, somente foram inventariadas na seca, por exemplo: Evolvulus lagopodioides, Paspalum polyphyllum e Trachypogon spicatus (grupo 6, Tab. 1).

As espécies do grupo 9 e 10 não foram registradas em todos os inventários realizados no campo sujo. Oito espécies apareceram apenas nos inventários efetuados na estação úmida (grupo 9, Tab. 1), enquanto outras três (grupo 10, Tab. 1) não foram amostradas em alguns inventários efetuados em meses de estação úmida.

Verificou-se uma variação no número de espécies entre as quatro linhas amostradas. Na linha CS1 registrou-se 92 espécies, e nas linhas CS2, CS3 e CS4 foram inventariadas 112, 94 e 82 espécies, respectivamente. No campo sujo da FAL, $87 \%$ das espécies ocorreram em pelo menos duas linhas de amostragem. A similaridade florística foi alta na comparação entre as linhas de campo sujo, com valores entre 0,60 e 0,69 para o coeficiente de Sørensen. Quando foi considerada a cobertura das espécies pelo índice de Czekanowski a similaridade continuou alta, variando de $57 \%$ a $66,5 \%$.

As altas similaridades entre as parcelas obtidas pelos índices acima foram confirmadas pelo método de classificação TWINSPAN, que não apresentou divisões significativas que as separassem em grupos com composição de espécies similares e diferenciados entre si. Porém, verificou-se uma divisão das espécies em quatro grupos, considerando-se a primeira e a segunda divisão do TWINSPAN (Fig. 4). A primeira divisão do TWINSPAN separou de um lado as espécies com maiores taxas de cobertura e, do outro as com menores. As espécies reunidas no grupo de maior cobertura, juntas, acumulam $62,5 \%$ da cobertura e $48,4 \%$ da freqüência relativa total da área, respectivamente, enquanto o outro grupo representa apenas $23,8 \%$ da cobertura relativa e $22,9 \%$ da freqüência relativa.

\section{Discussão}

O campo sujo da FAL apresentou uma elevada riqueza florística semelhante à encontrada em outros estudos em cerrado sentido restrito realizados no Distrito Federal (Felfili et al. 1994; Silva \& Nogueira 1999) e em campo sujo no estado de São Paulo (Tannus \& Assis 2004). Porém, a composição de espécies foi bastante diferenciada da encontrada em estudos fitossociológicos do estrato herbáceo em cerrado sentido restrito no estado de São Paulo (Mantovani \& Martins 1993) e no Maranhão (Meirelles et al. 2002), e também diferente da composição florística do campo sujo analisado por Tannus \& Assis (2004), provavelmente devido às diferenças na quantidade de chuvas, na temperatura, mais elevada no estado do Maranhão, à ocorrência de geadas em São Paulo, e às diferenças nos fatores físicos e químicos do solo, além de fatores bióticos que determinam a distribuição das espécies. Assim como para o cerrado sentido restrito (Mantovani \& Martins 1993; Felfili et al. 1998), o estrato herbáceosubarbustivo de campo sujo variou na composição florística entre diferentes áreas. 


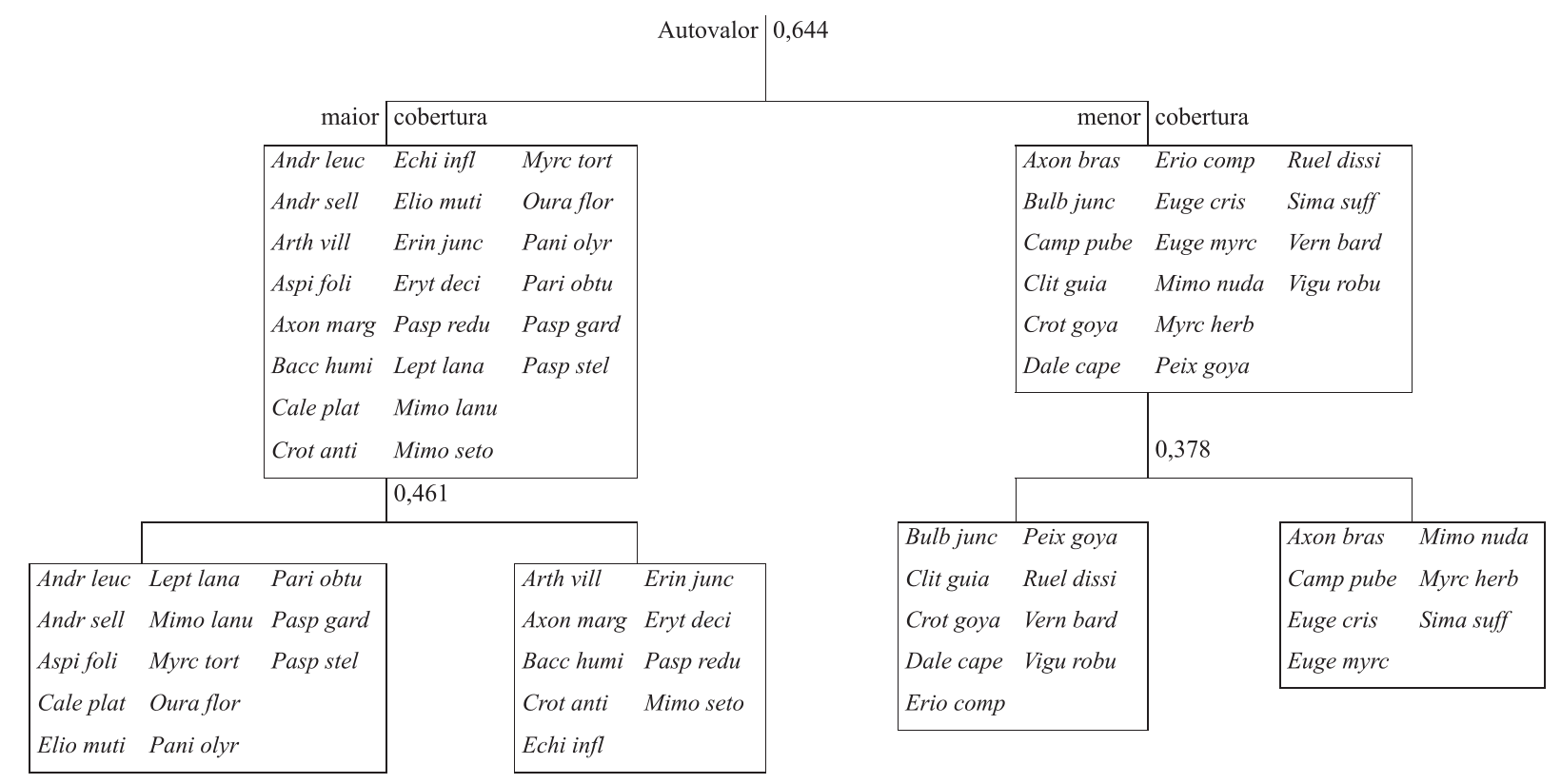

Figura 4. Classificação pelo método de TWINSPAN das espécies amostradas em uma área de campo sujo na Fazenda Água Limpa, Brasília, DF. As espécies estão identificadas pelas primeiras quatro letras do binômio, ver Tabela 1.

As espécies da família Poaceae apresentaram maior freqüência relativa, principalmente os gêneros Andropogon, Arthropogon, Axonopus, Echinolaena e Paspalum. Este padrão se repete no componente herbáceo de cerrado sentido restrito (Mantovani \& Martins 1993; Felfili et al. 1994; Silva \& Nogueira 1999). No entanto, embora a coincidência genérica entre o campo sujo da FAL e as áreas de cerrado sentido restrito mencionadas tenha sido alta, a coincidência ao nível de espécie foi baixa, indicando uma flora herbácea-subarbustiva de campo sujo distinta da de cerrado sentido restrito. Poucas espécies têm se apresentado com elevada abundância e distribuição em ambas as formações, como Echinolaena inflexa, considerada a espécie herbácea mais importante nos levantamentos fitossociológicos em áreas de cerrado sentido restrito (Felfili et al. 1994; Silva \& Nogueira 1999), tal qual nesse trabalho.

As espécies de Poaceae apresentaram sempre maior cobertura relativa que freqüência relativa, o que pode ser conseqüência da forma de crescimento de suas espécies que normalmente formam touceiras densas ou indivíduos rizomatosos ou estoloníferos amplamente espalhados na vegetação. Ao contrário, as espécies pertencentes às outras famílias mais importantes no campo sujo da FAL apresentam-se como ervas ou subarbustos pequenos e delgados distribuídos por toda a área, por isso com maior freqüência relativa do que cobertura relativa.

$\mathrm{Na}$ comunidade vegetal de campo sujo da FAL não houve uma variação sazonal acentuada na composição de espécies ao longo do período estudado, isto é, as taxas de cobertura das espécies mais importantes variaram pouco em um ano. Silva \& Nogueira (1999), estudando uma área de cerrado sentido restrito no Distrito Federal ao longo de um ano, obtiveram uma similaridade temporal ainda maior do que a encontrada neste trabalho. No entanto, a divisão das espécies em grupos por período de ocorrência observada nesse estudo, mostrou que para o estrato herbáceo-subarbustivo é necessário realizar mais de uma amostragem por ano, pois muitas espécies desse componente apresentam comportamento semelhante àquelas com ciclo de vida curto, sendo registradas por curtos períodos de tempo.

Algumas espécies como Acalypha claussenii, Campouloclinum megacephalum e Ichthyothere latifolia embora tenham sido amostradas nos inventários fitossociológicos somente 14 meses após o início do estudo, também foram registradas nos levantamentos florísticos realizados na área por C.B.R. Munhoz (dados não publicados) no mesmo ano deste trabalho. No entanto, espécies como, Cordia calocephala, Borreria tenella e Euphorbia sp. foram inventariadas somente no início do estudo e, não foram coletadas nos levantamentos florísticos realizados por 
C.B.R. Munhoz (dados não publicados). Outras espécies, como Esterhazya splendida e Galianthe ramosa, foram coletadas no levantamento florístico, anteriormente citado, no mesmo período um ano antes do seu registro nos inventários fitossociológicos. Esta variação no registro de algumas espécies entre os inventários e o levantamento florístico sugere que, além de ciclo de vida curto, algumas espécies têm estratégias diferenciadas de estabelecimento no tempo e no espaço.

A demora no estabelecimento de algumas espécies após o fogo e as variações no crescimento vegetativo entre as espécies, condicionadas à sazonalidade, podem ter sido determinantes da variação temporal nas taxas de cobertura entre as espécies no campo sujo estudado. As espécies que diferiram no tempo de ocorrência apresentaram baixas porcentagens de cobertura, sendo, principalmente, espécies de ciclo de vida curto ou com crescimento vegetativo sazonal, que somente são registradas em um determinado período.

A permanência da maioria das espécies na vegetação ao longo de todo o ano de estudos, ou na maioria dos períodos de amostragem, deveu-se provavelmente ao tempo de amostragem, que não foi suficiente para suprimir as espécies que têm dificuldade de crescer quando a massa vegetal seca e as espécies mais agressivas tornam-se mais densas.

O fogo possivelmente favoreceu poucas espécies, tais quais Cordia calocephala, Borreria tenella e Euphorbia sp., que só foram registradas nos primeiros inventários fitossociológicos e florísticos (C.B.R Munhoz, dados não publicados). Estudos com Gramíneas na Venezuela mostraram que o fogo pode favorecer espécies anuais, pois essas sendo menores e mais delicadas têm dificuldades de crescer sobre a massa vegetal seca acumulada no estrato herbáceosubarbustivo sem fogo (Canales et al. 1994). Áreas de campo sujo de cerrado sujeitas a queimadas periódicas são mais ricas em espécies do que áreas onde o fogo é suprimido por longo período de tempo (H.L. César, dados não publicados).

Algumas espécies foram registradas no campo sujo da FAL somente a partir do segundo inventário e outras aumentaram suas taxas de cobertura na área depois deste, sugerindo um maior tempo para o estabelecimento após o fogo. Echinolaena inflexa, por exemplo, apresentou apenas $6,0 \%$ de cobertura relativa em novembro de 1999 , chegando a $21,9 \%$ em julho/2000 e a 13,3\% em dezembro. Echinolaena inflexa produziu duas vezes mais sementes em uma área protegida do que em uma área queimada (L.M.
Parron, dados não publicados). Diminuição no número de espécies após incêndio foi observada por A.A.A. Barbosa (dados não publicados), em uma área de campo sujo em Uberlândia, Minas Gerais. Aumento de mortalidade e redução no crescimento foi verificado em gramíneas Venezuelanas após o fogo (Canales \& Silva 1987; Silva et al. 1991). A ocorrência freqüente de fogo em áreas de cerrado afeta negativamente a comunidade lenhosa provocando uma diminuição na diversidade de espécies (Eiten \& Sambuichi 1996) e um aumento na mortalidade de indivíduos (Sato \& Miranda 1996). Assim, como para o estrato lenhoso, o fogo pode levar à diminuição da diversidade no estrato herbáceo-subarbustivo de campo sujo, provavelmente pelo aumento das populações de espécies mais tolerantes que se tornariam competidoras, ou pela diminuição da capacidade reprodutiva de algumas espécies, ou pelo aumento nas taxas de mortalidade de outras. Estudos de longa duração comparando áreas de campo sujo isentas de queimadas e sujeitas a fogo periódico, serão necessários para se verificar o efeito do fogo nesta comunidade.

Muitas espécies não foram registradas no auge da estação seca, entre elas Bauhinia sp.1, Calea gardneriana, Cuphea spermacoce, Kielmeyera abdita e Mimosa xanthocentra, e outras reduziram muito a cobertura, como Byrsonima rigida, Campomanesia pubescens, Clitoria guianensis, Croton antisyphiliticus e Croton campestris. Estas espécies apresentaram crescimento epígeo sazonal similar ao descrito por Eiten (1993) que verificou que a parte aérea de muitas plantas herbáceas e subarbustivas de cerrado morre completamente anualmente e é substituída a cada estação chuvosa. No entanto, a seca não restringiu o aumento de cobertura de algumas espécies e o aparecimento de outras no campo sujo. A ocorrência de algumas espécies somente no inventário de julho e o aumento nas taxas de cobertura de outras nesse período mostra que a seca não restringe totalmente o brotamento, $o$ estabelecimento e o crescimento no campo sujo. Isto reflete uma estratégia reprodutiva que apresenta crescimento vegetativo e reprodutivo concomitante, com dispersão de diásporos no final da seca e germinação logo no início das chuvas.

Para aumentar as chances de se inventariar um maior número de espécies do estrato herbáceosubarbustivo de campo sujo, esse estudo sugere que os inventários sejam realizados pelo menos no auge da estação úmida, quando foram registradas as maiores porcentagens de cobertura, e no início da estação seca 
quando foram amostradas muitas espécies com ciclo de vida curto e com crescimento vegetativo sazonal.

A alta similaridade entre as linhas no campo sujo é resultante na homogeneidade edáfica dessa fitofisionomia de cerrado (C.B.R Munhoz, dados não publicados). Indicando, assim, que para essa vegetação poucas linhas podem amostrar suficientemente bem suas espécies. A homogeneidade das linhas pode ser confirmada pelo método de agrupamento do TWINSPAN que não mostrou uma separação significativa das transecções. Porém, o TWINSPAN mostrou o agrupamento das espécies com maiores coberturas separando-as daquelas com menores taxas de cobertura. A forma de crescimento dessas espécies com maiores porcentagens de cobertura formando touceiras densas, como ocorre em Andropogon leucostachyus, Arthropogon villosus e Axonopus marginatus, ou ervas bastante espalhadas na vegetação devido a grande produção de rizomas, como é o caso de Echinolaena inflexa, pode ser um fator limitante para aquelas menores e mais delgadas na vegetação, oferecendo a elas maior sombreamento e aumento de competição por nutrientes para se estabelecer.

Para o estrato herbáceo-subarbustivo de campo sujo as evidências de mudanças na estrutura e na riqueza florística apresentadas neste estudo ao longo de um ano, sugerem que a espécies deste ecossistema respondem à sazonalidade climática da região e ao fogo. Porém, observações em diferentes localidades e por um maior período de tempo, comparando áreas queimadas e não queimadas, devem ser efetuadas para se detectar padrões na distribuição espacial e temporal de plantas do estrato herbáceo-subarbustivo de campo sujo.

\section{Agradecimentos}

As autoras agradecem à Kennya Mara Oliveira Ramos e ao Newton Rodrigues, pelo apoio e auxílio no trabalho de campo; a CAPES, pela bolsa de doutorado concedida para a primeira autora; ao DFID-UK, PRONEX-2 e CNPq-PELD, pelo apoio financeiro que permitiu consolidar a infra-estrutura necessária para a execução deste projeto.

\section{Referências bibliográficas}

Angiosperm Phylogeny Group (APG). 2003. An update of the angiosperm phylogeny group classification for the orders and families of flowering plants: APGII. Botanical Journal of the Linnean Society 141(4): 399-436.
Batalha, M.A. \& Martins F.R. 2002. The vascular flora of the cerrado in Emas National Park (central Brazil). Sida 20(1): 295-312.

Canales, J. \& Silva J.F. 1987. Efecto de uma quema sobre el crecimiento y demografia de vástagos em Sporobolus cubensis. Acta Oecologica 8(2): 391-401.

Canales, J.; Trevisan, M.C.; Silva, J.F. \& Caswell, H. 1994. A demographic study of an annual grass (Andrpogon brevifolius Schwrz) in burnt and unburnt savanna. Acta Oecologica 15(3): 261-273.

Canfield, R. 1941. Application of line interception in sampling range vegetation. Journal of Forestry 39(5): 388-394.

Canfield, R. 1950. Sampling range by the line interception method. Southwestern Forest and Range Experiment Station.

Coutinho, L.M. 1982. Ecological effect of fire in Brazilian cerrado. Pp. 273-291. In: B.J. Huntley \& B.H. Walker (eds.). Ecology of tropical savannas. Berlin, SpringerVerlag.

Coutinho, L.M. 1977. Aspectos ecológicos do fogo no cerrado. II. As queimadas e a dispersão em algumas espécies anemocóricas do estrato herbáceo subarbustivo. Boletim de Botânica da Universidade de São Paulo 5: 57-64.

Coutinho, L.M. 1979. Aspectos do fogo no cerrado. III- A precipitação atmosférica de nutrientes minerais. Revista Brasileira de Botânica 2: 97-101.

Eiten, G. 1979. Formas fisionômicas do Cerrado. Revista Brasileira de Botânica 2: 139-148.

Eiten, G. 1992. Natural brazilian vegetation types and their causes. Anais da Academia Brasileira de Ciência 64(Suppl. 1): 35-65.

Eiten, G. 1993. Vegetação do Cerrado. Pp. 17-74. In: M. Novaes Pinto (ed.). Cerrado: caracterização, ocupação e perspectivas Brasília. Brasília, Editora Universidade de Brasília.

Eiten, G. \& Sambuichi, R.H. 1996. Effect of long-term periodic fire on plant diversity in a cerrado region. Pp. 46-55. In: R.C. Pereira \& L.C.B. Nasser (eds.). Biodiversidade e produção sustentável de alimentos e fibras nos cerrado. Anais/Proceeding do VIII Simpósio sobre o cerrado.

Felfili, J.M. 1998. Determinação de padrões de distribuição de espécies em uma mata de galeria no Brasil Central com a utilização de técnicas de análise multivariada. Boletim do Herbário Ezechias Paulo Heringer 2: 35-48.

Felfili, J.M.; Filgueiras, T.S.; Haridasan, M.; Silva Junior, M.C.; Mendonça, R.C. \& Resende, A.V. 1994. Projeto Biogeografia do Bioma Cerrado: Vegetação \& Solos. Caderno de Geociências 12(4): 75-166.

Felfili, J.M.; Silva Junior, M.C.; Filgueiras, T.S. \& Nogueira, P.E. 1998. Comparasion of cerrado (sensu stricto) vegetation in Brasil Central. Ciência e Cultura 50(4): 237-243.

Gauch, H.G. 1982. Multivariate Analysis in Community Ecology. Cambridge, Cambridge University Press.

Goldsmith, F.B. 1974. Multivariate analyses of tropical grassland communities in Mato Grosso, Brazil. Journal of Biogeography 1(2): 111-122. 
Guimarães, A.J.M.; Araújo, G.M. \& Corrêa, G.F. 2002. Estrutura fitossociológica em área natural e antropizada de uma vereda em Uberlândia, MG. Acta Botanica Brasilica 16(3): 317-330.

Haridasan, M. 1996. Estresse nutricional. Pp. 27-30. In: B.F.S Dias (ed.). Alternativas de desenvolvimento dos cerrados: Manejo e conservação dos recursos naturais renováveis. Brasília, FUNATURA.

Hill, M.O. 1979. TWINSPAN - a FORTRAN program for arranging multivariate data in an ordered two-way table by classification of the individuals and attributes. New York, Cornell University, Ithaca.

Kent, M. \& Coker, P. 1992. Vegetation description and analysis; a pratical approach. London, Belhaven Press.

Kovach, W.L. 1993. MVSP (Multivariate Statistical Package). Kovach PLC.

Mantovani, W. \& Martins, F.R. 1993. Florística do Cerrado na reserva biológica de Moji-Guaçu, SP. Acta Botanica Brasilica 7(1): 33-60.

Magurran, A.E. 1988. Ecological diversity and its measurements. London, Croom Helm.

Meirelles, M.L.; Oliveira, R.C.; Ribeiro, J.F.; Vivaldi, L.J.; Rodrigues, L.A. \& Silva, G.P. 2002. Utilização do método de interseção na linha em levantamento quantitativo do estrato herbáceo do cerrado. Boletim do Herbário Ezechias Paulo Heringer 9: 60-68.

Mendonça, R.C.; Felfili, J.M.; Walter, B.M.T.; Silva Júnior, M.C.; Rezende, A.V.; Filgueiras, T.S. \& Nogueira, P.E. 1998. Flora vascular do Cerrado. Pp. 289-556. In: S.M. Sano \& S.P. de Almeida (eds.). Cerrado: ambiente e flora. Planaltina, EMBRAPA-CPAC.
Moreira, A.G. 1996. Proteção contra fogo e seu efeito na distribuição e composição de espécies de cinco fisionomias de cerrado. Pp. 112-121. In: H.S. Miranda; C.H. Saito \& B.F.S. Dias (eds.). Impactos de queimadas em áreas de cerrado e restinga. Brasília, Universidade de Brasília.

Mueller-Dombois, D. \& Ellenberg, H. 1974. Aims and methods of vegetation ecology. New York, Willey and Sons.

Munhoz, C.B.R. \& Felfili, J.M. 2005. Fenologia do estrato herbáceo-subarbustivo de uma comunidade de campo sujo na Fazenda Água Limpa no Distrito Federal, Brasil. Acta Botanica Brasilica 19(4): 981-990.

Ribeiro, J.F. \& Walter, B.M.T. 1998. Fitofisionomias do Bioma Cerrado. Pp.98-166. In: S.M. Sano \& S.P. Almeida (eds.). Cerrado: ambiente e flora. Planaltina, EMBRAPA-CPAC.

Sato, M.N. \& Miranda, H.S. 1996. Mortalidade de plantas lenhosas do cerrado sensu stricto submetido a diferentes regimes de queima. Pp. 102-111. In: H.S. Miranda; C.H. Saito \& B.F.S. Dias (eds.). Impactos de queimadas em areas de cerrado e restinga. Brasilia, Universidade de Brasília.

Silva, J.F.; Raventos, J.; Caswell, H. \& Trevisan, M.C. 1991. Population responses to fire in a tropical savanna grass, Andropogon semiberbis: a matrix model approach. Journal of Ecology 79(2): 345-356.

Silva, M.A. \& Nogueira, P.E. 1999. Avaliação fitossociológica do estrato arbustivo-herbáceo em cerrado stricto sensu após incêndio acidental, no Distrito Federal, Brasil. Boletim do Herbário Ezechias Paulo Heringer 4: 65-78.

Tannus, J.L.S. \& Assis, M.A. 2004. Composição de espécies vasculares de campo sujo e campo úmido em área de cerrado, Itirapina - SP, Brasil. Revista Brasileira de Botânica 27(3): 489-506. 